

\title{
Review
}

\section{Do training programs improve a paramedic's ability to identify and report child abuse and neglect? A systematic review}

Kate Brooke Johnson MD Candidate 2019¹, Elizabeth Doecke MD, BSc (BioMed Hons) is an Intern², Raechel A Damarell BA, GradDiplnfoStud is a PhD Candidate ${ }^{3}$, Hugh Grantham MBBS, FRACGP is Professor of Paramedics ${ }^{1}$

\author{
Affiliations: \\ ${ }^{1}$ School of Medicine, Flinders University, Adelaide, South Australia \\ ${ }^{2}$ Flinders Medical Centre, Adelaide, South Australia \\ ${ }^{3}$ College of Nursing and Health Sciences, Flinders University, Adelaide, South Australia
}

\section{Abstract}

\section{Introduction}

Paramedics are often the first trained personal to assess sick or injured children. This raises the question of how well trained paramedics are to identify signs of child abuse or neglect. This systematic literature review seeks to establish the extent to which training programs improve a paramedic's competence and confidence when it comes to identifying and reporting child abuse and neglect.

\section{Methods}

Selected search terms were entered into eight databases to identify potentially relevant publications. Inclusion and exclusion criteria were applied and articles were categorised as relevant or irrelevant based on a review of title and abstract and, when necessary, full text review.

\section{Results}

The initial electronic search yielded 872 articles. After duplicates were removed and the inclusion and exclusion criteria applied, four publications were identified as relevant and included in this systematic literature review. Of these, three were cross-sectional studies and one was a one-group pre-test post-test study. In total, 2499 subjects were examined across the four articles. Despite the limitations of each study, the results for all four studies were consistent with one another, demonstrating that higher levels of training correlated with greater knowledge and/or confidence regarding both the identification process and the correct procedures for reporting child abuse.

\section{Conclusion}

The limited evidence published so far suggests that training improves confidence and ability levels of the paramedic in recognising and reporting child abuse. However, the limitations of these studies need to be considered before drawing robust conclusions. We call for further research into the topic and suggest that, owing to the complexity of the issue, a qualitative study may be the best way of exploring the variety of barriers to reporting, and the extent to which training would overcome these.

Keywords:

paramedics; emergency medical technicians; mandatory reporting; child abuse; in-service training 


\section{Introduction}

Paramedics are frequently the first health professionals to examine and assess injured children. This raises the question of how well trained paramedics are to differentiate accidental injury from abuse or neglect, as well as other signs of child maltreatment. This systematic literature review seeks to establish the extent to which training programs improve a paramedic's competence and confidence when it comes to identifying and reporting child abuse and neglect. Given that paramedics are mandated notifiers in several states of Australia, this role needs to be supported by sufficient training.

\section{Child maltreatment as a major health issue}

It is known that adverse childhood events have both short and long term effects on health $(1,2)$ and that early intervention, often initiated by mandated notification, has significant protective impacts (3), thus rendering the issue of effective training of critical importance.

There are well-established links between multiple exposures to adverse childhood events and increased odds of adverse outcomes in adulthood, including ischaemic heart disease, stroke, chronic bronchitis, emphysema, diabetes, cancer and attempted suicide $(1,2)$. This phenomenon is observed even after adjusting for socio-economic factors and is not limited to the impacts of risky behaviours such as smoking (2). This renders childhood abuse a major public health issue, both in the short and long term.

\section{The importance of mandatory notifications in Australia} In Australia in 2014-15 more than 42,000 children were the victims of abuse. The median age of children involved with child protection services was just 7 years of age, with infants under 1 year of age having the strongest representation. These statistics are still likely to be understated, as many health professionals may under-report child abuse and neglect $(4,5)$. Mandated notifiers are required by law to make a notification if there is suspicion of abuse. A New South Wales report on mandatory notification revealed that the majority of notifications received by child protection services come from mandated reporters (6), thus further highlighting the importance of ensuring that mandated reporters are familiar with the role of notification and how to report. The laws that determine which individuals are mandated notifiers vary from state-to-state, however most encompass professions that supply services to children, particularly those in the public sector (7).

There are few published studies examining mandated notifications by health professionals in general, however those that do reveal numerous potential barriers experienced by individuals regarding mandated notifications $(3,5,8,9)$. An examination of these barriers suggests that current levels of training provided to health professionals in the area of reporting child abuse are inadequate, especially with regards to what constitutes child abuse, appropriate documentation and reporting procedures $(10,11)$.

\section{Unique opportunities for paramedic observations}

Paramedics are an important subgroup of mandated notifiers. They are in a unique position to recognise and report child abuse having access into, often at short notice, the home of a child in a context that is generally not accessible to other health professionals $(3,12)$.

\section{The role of training}

When it comes to changing behaviours of individuals, training is a commonly employed strategy. It is intended that through this systematic review, we will understand how effective training is as a means of decreasing underreporting of child abuse among paramedics.

Despite any logical assumptions about transferability of training methods used from one profession to another, the authors have been careful not to assume that any and every type of training would necessarily increase competence or confidence for paramedics, particularly in the long term.

The aim of this systematic review is to collate, and provide a non-biased review of published research on paramedic training in relation to the identification and reporting of child abuse and neglect. To this end, it will evaluate:

- the evidence of training and its impact on the frontline paramedic's overall confidence and competence in identifying and reporting child abuse and neglect

- features of successful programs in this field

- consensus of opinion as to which aspects of identification and reporting should be included in the syllabus of such training programs.

\section{Methods}

\section{Eligibility criteria}

Studies were selected according to the criteria outlined below.

\section{Intervention}

We sought studies describing formal training in frontline identification and mandatory reporting of abuse and neglect of children (0-12 years).

\section{Population}

Only studies exploring outcomes for paramedics, ambulance officers or emergency services technicians or personnel were included. In the absence of a sufficiently broad pre-existing working definition, the authors defined 'paramedics' as those who serve in a paid or voluntary capacity as healthcare workers, working predominately in the pre-hospital environment in a paramedic role. 
Participants were included if their level of training was appropriate to provide frontline medical intervention in the state or country in which the study was performed, noting that this training ranged from certificate level to diplomas or degrees depending on the location. By using this deliberately broad definition, paramedics from any geographical region were included.

\section{Outcomes}

To be considered, studies needed to evaluate the effect of training on at least one of the following outcomes:

- confidence in identifying child abuse or neglect

- competence in identifying child abuse or neglect

- confidence in reporting child abuse or neglect

- competence in reporting child abuse or neglect.

\section{Settings}

There were no restrictions by type of setting.

\section{Levels of evidence}

We included all primary studies with an experimental or observational methodology designed to objectively measure, or find an association between, our outcomes of interest. We excluded case reports, narrative reviews, and expert opinions.

\section{Language}

We included articles reported in the English language only.

\section{Exclusion criteria}

We excluded all studies in which:

- paramedics (including ambulance officers, emergency services personnel/technicians) were not the primary population focus, or were included but not separated from other health professionals

- the focus was based on clinical or procedural interventions, rather than on training regarding the identification and reporting of child abuse

- training focussed on responses to specific paediatric pathologies of which child abuse was only one of many potential aetiologies (eg. burns, long bone fractures, head injuries)

- the focus was on a paramedic's personal history of child abuse as a predisposing risk factor for adverse mental health outcomes.

\section{Information sources}

The literature search strategy was initially informed by a scoping search of key databases such as Ovid Medline. This process identified relevant database-specific subject headings, as well as natural language terms for each of our concepts. Once satisfied that the search was sufficiently sensitive to ensure that potentially relevant studies would not be missed, the search was accurately translated for other databases. These included PubMed, CINAHL, Scopus, Web of Science, PsycINFO (Ovid), Informit (all databases) and a range of ProQuest databases (including ERIC and Sociological Abstracts).

Study authors were contacted when further clarification was required to interpret methodology or results. As a final check, we also reviewed the reference lists of included studies for additional relevant citations.

\section{Search strategy}

The search was not restricted to types of studies, date range or geographic region. We did, however, limit to English language publications. All searches were executed on 9 November 2015.

\section{Data management}

All citations were downloaded to an EndNote X7 library and then duplicates were removed. This program was used to sort citations into the categories of relevant, irrelevant or of uncertain relevance. It was also used to store the full text articles when these were required to make an inclusion decision.

Screening for relevant studies against the eligibility criteria was carried out in two stages. The primary author (KJ) initially screened all retrieved citations based on title and abstract only. To minimise the risk of selection bias, the second author (ED) independently screened a random sample of $20 \%$ of these citations, again based on title and abstract. Both authors then reviewed the full-text of all remaining citations. Decision discrepancies were resolved by discussion.

Study quality was assessed using the Effective Public Health Practice Project Quality Assessment Tool for Quantitative Studies (13). Data was extracted using standardised table devised a priori.

\section{Results}

The search process identified 872 citations, which was reduced to 647 once duplicates were removed.

The primary author (KJ) screened these articles by title and abstract and excluded 616 as irrelevant to the review criteria. The second author (ED) independently screened the titles and abstracts of a random selection of 130 articles ( $20 \%)$. Two authors (KJ and ED) then screened the remaining 31 articles on full-text (where available) and 24 articles were excluded based on their failure to meet the study criteria. Of the remaining seven titles, two were excluded because they were published as abstracts only and were based on the same data, later published within one full-text article. A third article was also excluded because it was found to be the precursor to a later published article based on the same data. This left four full-text articles that fulfilled the study criteria. This process is illustrated in the PRISMA flow diagram (14) included as Figure 1. 


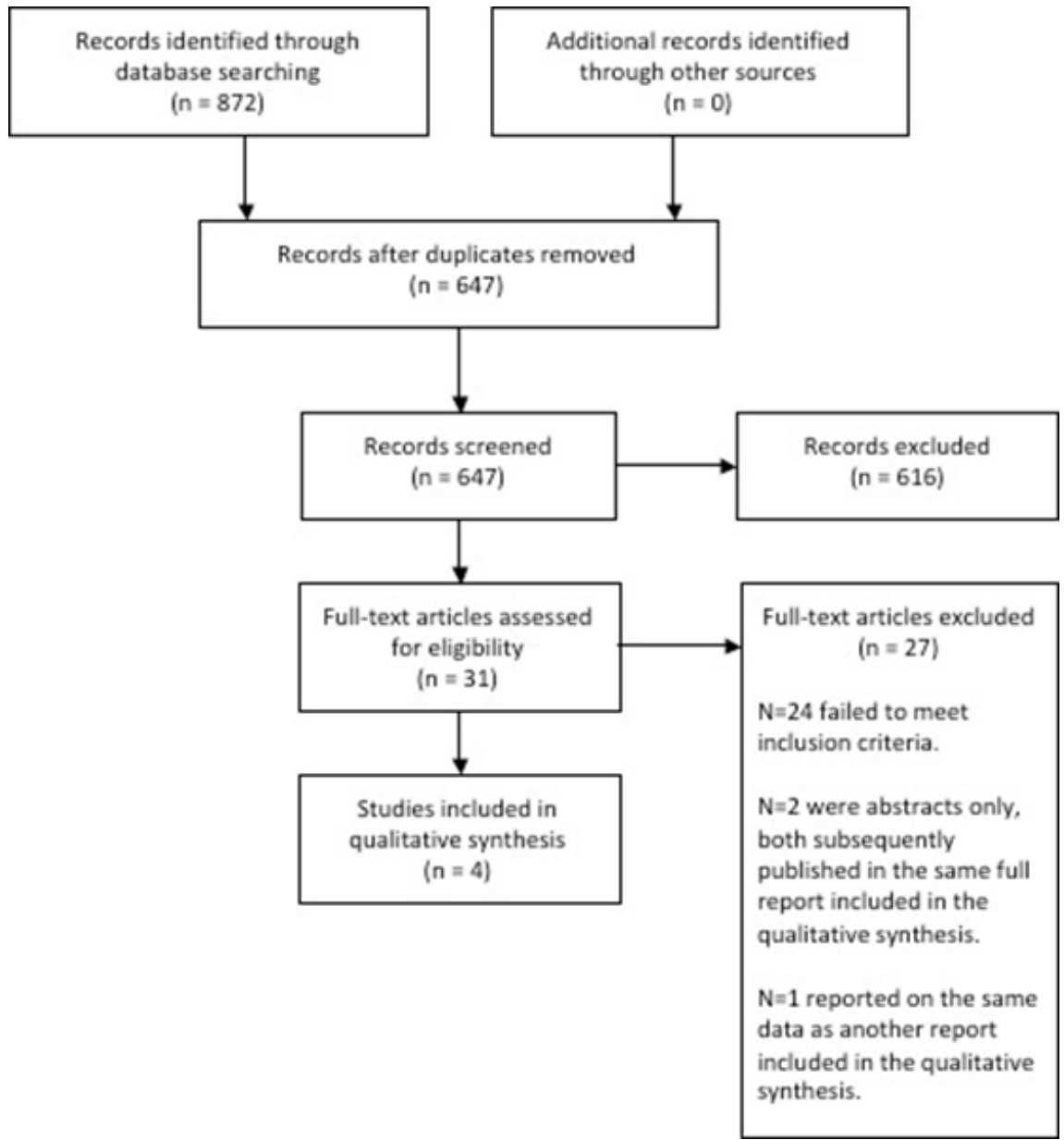

Figure 1. Flow chart of screening decisions made against eligibility criteria

From the published literature, we found four articles that met our inclusion criteria and merited further analysis. These are described in Table 1.

\section{Methodology}

Three of the studies were cross-sectional and one used a pretest post-test design (15).

\section{Population}

In total, 2499 subjects were examined across the four articles.

The cross-sectional studies comprised 2071 subjects and the pre-test post-test student comprised 428 subjects. The overwhelming majority (2495) of participants were paramedics or emergency medical technicians. All study populations resided within the United States (US).

\section{Validation}

Validity of the data collection instrument was established in two of the cross-sectional studies $(11,16)$ but was not established nor described in the smallest cross-sectional study (10) and the one-group pre-test post-test study. These leaves the latter two studies open to the possibility of measurement and detection bias.

\section{Outcomes measured}

King (10) assessed knowledge about child abuse and the reporting thereof, and attitudes towards child abuse. Knowledge retention and familiarity with assessment, reporting and intervention protocols were assessed by Weintraub (15). Stevens and Alexander (16) specifically measured comfort levels of paramedics in relation to aspects of paediatric care, including child abuse. Markenson (11) assessed knowledge, attitudes, confidence and training needs regarding situations of child abuse.

\section{Study quality}

Study quality was found to be limited in all cases. Where it was thought that our interpretation of the studies would be enhanced by further information, we wrote to the relevant authors. These communications did not reveal any further information that increased our assessment on the quality of these studies, as discussed below. 
Table 1. Characteristics of included studies

\begin{tabular}{|c|c|c|c|c|}
\hline Study & $\begin{array}{l}\text { Title, journal and country } \\
\text { of origin }\end{array}$ & Methodology & $\begin{array}{c}\text { Number of respondents and } \\
\text { types of participants }\end{array}$ & $\begin{array}{l}\text { Outcomes } \\
\text { measured }\end{array}$ \\
\hline $\begin{array}{l}\text { King et al. } 1993 \\
\text { (10) }\end{array}$ & $\begin{array}{l}\text { Reporting of child abuse by } \\
\text { pre-hospital personnel } \\
\text { Prehospital and Disaster } \\
\text { Medicine } \\
\text { USA }\end{array}$ & $\begin{array}{l}\text { Cross-sectional } \\
\text { study }\end{array}$ & $\begin{array}{l}\mathrm{N}=48 \\
\text { Pre-hospital caregivers who } \\
\text { were participants in a seminar } \\
\text { on paediatric emergencies }\end{array}$ & $\begin{array}{l}\text { Knowledge about } \\
\text { child abuse and } \\
\text { reporting thereof } \\
\text { Attitudes towards } \\
\text { child abuse }\end{array}$ \\
\hline $\begin{array}{l}\text { Weintraub et al. } \\
2002(15)\end{array}$ & $\begin{array}{l}\text { Child maltreatment } \\
\text { awareness of pre-hospital } \\
\text { providers } \\
\text { International Journal of } \\
\text { Trauma Nursing } \\
\text { USA }\end{array}$ & $\begin{array}{l}\text { One group were } \\
\text { given a pre-test } \\
\text { and then a post- } \\
\text { test following } \\
\text { an educational } \\
\text { program }\end{array}$ & $\begin{array}{l}\mathrm{N}=177 \\
\text { Paramedics who attended } \\
\text { an educational program } \\
\text { addressing the assessment of } \\
\text { child maltreatment, reporting } \\
\text { laws and procedures for } \\
\text { intervention }\end{array}$ & $\begin{array}{l}\text { Knowledge retention } \\
\text { Familiarity with } \\
\text { assessing, reporting } \\
\text { and intervening in } \\
\text { situations of child } \\
\text { abuse }\end{array}$ \\
\hline $\begin{array}{l}\text { Stevens et al. } \\
2005(16)\end{array}$ & $\begin{array}{l}\text { The impact of training } \\
\text { and experience on EMS } \\
\text { providers' feelings towards } \\
\text { paediatric emergencies in a } \\
\text { rural state } \\
\text { Paediatric Emergency Care } \\
\text { USA }\end{array}$ & $\begin{array}{l}\text { Cross-sectional } \\
\text { study }\end{array}$ & \begin{tabular}{|l}
$\mathrm{N}=786$ \\
A postal survey was distributed \\
to all those who were \\
registered EMTs in the state \\
of Maine (USA). It relied on \\
voluntary responses
\end{tabular} & $\begin{array}{l}\text { Comfort levels of } \\
\text { providers regarding } \\
\text { aspects of paediatric } \\
\text { care, including child } \\
\text { abuse }\end{array}$ \\
\hline $\begin{array}{l}\text { Markenson et al. } \\
2007 \text { (11) }\end{array}$ & $\begin{array}{l}\text { A national assessment of } \\
\text { knowledge, attitudes and } \\
\text { confidence of prehospital } \\
\text { providers in the assessment } \\
\text { and management of child } \\
\text { maltreatment } \\
\text { Paediatrics } \\
\text { USA }\end{array}$ & $\begin{array}{l}\text { Cross-sectional } \\
\text { study }\end{array}$ & $\begin{array}{l}\mathrm{N}=1237 \\
\text { A randomly selected population } \\
\text { of pre-hospital providers who } \\
\text { were qualified at the EMT- } \\
\text { basic or EMT-paramedic level } \\
\text { to be representative of the } \\
\text { nation wide EMS practitioners }\end{array}$ & $\begin{array}{l}\text { Knowledge, attitude, } \\
\text { confidence and } \\
\text { training needs } \\
\text { regarding situations } \\
\text { of child abuse }\end{array}$ \\
\hline
\end{tabular}

\section{Discussion}

This discussion provides a thematic analysis of the key themes in the included studies and considers the limitations associated with these same studies.

\section{Impact of training on paramedic competence and confidence}

The results for all four studies were consistent with one another, and demonstrated that higher levels of training correlated with greater knowledge and/or confidence regarding both the identification process and the correct procedures for reporting child abuse.

King (10) found that pre-hospital personnel who had reported specific training on child abuse were more likely to correctly identify the role of a mandated reporter, and more likely to have followed correct reporting procedure.

Weintraub (15) found that a continuing education program on child maltreatment identification, reporting and interventions resulted in improvements in knowledge in the areas of definitions and reporting requirements.

Stevens and Alexander (16) found a significant association $(p<0.05)$ between additional hours of continuing education and increased comfort in confronting situations of child abuse.

Markenson (11) found that the presence of child maltreatment education during initial training and during continuing medical education were both significantly associated $(p<0.01)$ with correct answers in both cognitive knowledge of child abuse and assessment of scenarios of child abuse.

\section{Issues in understanding the impact of training}

To avoid bias, the authors have not made any assumptions about transferability of training methods used from one profession to another, particularly in the long term. This is due to the lack of frequent exposure that paramedics have to paediatric patients, in addition to the broad range of situations and pathologies that paramedics are already required to train for. 
Several studies describe how paramedics' confidence levels improve immediately after a paediatric airway management training program, then decline with time $(17,18)$. Furthermore, the number of paramedics able to adequately perform these airway management skills dropped significantly over time to the extent that 6 months after the training workshop $61 \%$ would not pass a clinical skills assessment. Therefore, it is particularly important to look at the type and frequency of training delivered in order to understand how effective it is.

\section{Limitations of the included studies}

Despite the consistency in results, all four studies had limitations. The articles with the two smallest sample groups, King (10) and Weintraub (15), lacked information regarding sampling methods, failing to report the original group sizes and why these participants were at the training workshops from which they were selected. These two articles also imply a voluntary participant response, which may have led to overestimating attitudes and interest in the subject. Furthermore, the Weintraub study (15) lacked information on the questions asked and did not provide a meaningful statistical breakdown of results. As such, this study is not replicable.

The third article by Stevens and Alexander (16) was a crosssectional study of 786 subjects, based on a postal survey to all emergency medical services (EMS) providers in the state of Maine. It yielded an overall $18 \%$ response rate of which $46 \%$ of responses were from volunteers. This significant inclusion of people motivated and passionate enough to volunteer as EMS workers and to voluntarily respond to a survey, make generalisability difficult and leaves the study susceptible to question of bias.

Furthermore, Stevens and Alexander's sample group was not described in detail, nor was the sample size justified. They also relied on perceptions of 'comfort', a subjective measure that is difficult to quantify in a meaningful and transferable way. In any case, Gausche-Hill found that perceived levels of comfort, or perceived need for training, often differ from tested realities and that such confidence levels often decline with time following training courses (17). Finally, Stevens and Alexander (16) do not state how informed consent was obtained, thus also leaving their study vulnerable to attention bias.

The Markenson study, involving the largest number of participants ( $n=1237)$, describes its methods and sample in detail and provides justification for size. However, their study design and reliance on voluntary responses for a survey that took 25-40 minutes to complete leaves it vulnerable to selection bias. Furthermore, as they also conclude, their results may overestimate attitudes and knowledge in this area. This study also refers to 'analysis of association using non-parametric tests' in the methodology, but no mention of these tests is subsequently made in the results. The study's discussion relies heavily on data from King (10). Three of the four studies were cross-sectional, and although this may have been appropriate for King (10), the first pilot study in this subject, it must be noted that one of the weaknesses with the cross-sectional survey is that it may demonstrate association but for complex subjects like this, it cannot prove causation (19). It cannot therefore provide evidence of effectiveness, particularly concerning training. The Weintraub study used a pre- and post-test methodology, however it is implied that the pre- and post-tests were taken at, or immediately following the training program, which makes it difficult to measure the long-term retention of skills.

A further limitation of these studies is that they fail to describe the content and quality of the education/training that subjects had been exposed to. We note that the one-group pre-test post-test study by Weintraub was an examination of a specific training program, however any prior training subjects may have received was not accounted for.

\section{Potential limitations to this systematic review}

While every effort has been made to ensure accuracy in our systematic review, there may be further databases that were not accessible to the authors. Furthermore, we did not explore the grey literature. Limiting to studies published in English may have excluded quality studies and contributed to bias in our conclusions.

\section{Paucity of published research}

Overall, this systematic review found a noteworthy paucity of published research on the effectiveness of training programs designed to equip paramedics to be mandatory reporters of child abuse. Indeed, King correctly points out that there were no other published articles on this topic before their 1993 study. Furthermore, the most recently published article, Stevens and Alexander was only able to cite the work of King (10) as relevant background literature, again demonstrating a lack of research undertaken in this area. This is particularly concerning given the widespread and serious nature of the issue, and the extent to which paramedics could potentially screen large sections of the community (15).

The authors suggest that the lack of research on this subject stems from one or more of the following factors:

- Although paramedics have access to the home environment of the injured child and are often the first to assess injuries and caregiver attitudes, their potential contribution towards child protection may not yet be recognised

- Research on the skills needed to identify and report child abuse may be assumed transferable from research carried out on other professions. For example, it may be the case that more research has been undertaken regarding school teachers or nurses as mandated reporters, and paramedic trainers may have simply assumed that the same training program principles should be applied to paramedic education 
- Without a national training standard, it may be assumed that such training is integrated on a course-by-course basis

- It may be assumed that the training paramedics receive in injury recognition is sufficient for them to differentiate accidental from intentional injury

- Child abuse is a difficult area to investigate due to its hidden nature and the complex sociology associated with the settings in which it occurs.

\section{Implications for research}

Whether any or all of the aforementioned points accurately represent the reasons for the lack of research, we believe the need for urgent further research should not be dismissed. Indeed, all studies examined in this article provide solid justifications for the ongoing need for further research into this topic, describing the widespread impact of child abuse, for which paramedics are in a unique position to identify and report. Of note, Weintraub (15) states that while only $10 \%$ of their EMS calls were for paediatric patients, it is believed that over $50 \%$ of their callouts are to households where children are present. This again highlights that appropriately trained EMS workers would have the opportunity to screen a large proportion of homes for signs of child maltreatment.

\section{Implications for paramedic curricula design}

The competencies for paramedics set out by the Australian paramedics' professional body include the ability of the paramedic to 'undertake a comprehensive assessment of the patient, which includes assessment of the psychological, social and cultural determinants of health' (20). Given that the presence of child abuse is an established determinant of health (2), it follows that this topic ought to be included in every paramedic training program.

Barriers to reporting child abuse or neglect are very real. Two Australian studies have identified the following barriers for health professionals making mandated notifications: a belief that the abuse was unlikely to reoccur; acceptance of the explanation given for the injury; lack of faith in the efficacy of the child protection system; and a desire to wait for more conclusive evidence $(8,9)$.

In the US, Concialdai and Read (5) examined underreporting of child abuse and concluded that it is largely due to confusion regarding who to report to, what should prompt a report and what information should be included in a report. Other factors include fear of prompting unnecessary child removal, reluctance to be involved in a drawn-out legal process, and a lack of belief in the efficacy of reporting. In addition, opportunities for early intervention may be missed as health professionals may not feel sufficiently certain that abuse has taken place, lack knowledge around what circumstances ought to be reported, or may not know the processes for making a report (3). The belief that someone else will make the report is another contributing factor to underreporting. Indeed, these cited reasons suggest that current levels of training provided to health professionals in the area of reporting child abuse are inadequate, especially with regards to knowledge of what constitutes child abuse, appropriate documentation and reporting procedures $(10,11)$.

There may also be consequences, both positive and negative, for the individual making the notification. These include feelings of self-doubt regarding the accuracy of their assessment, guilt for making the report and emotional energy required to make a report. These types of impacts should be considered when trying to determine the extent to which training will change reporting rates.

\section{Conclusion}

This systematic review has highlighted the need for further study in this area. Given the complexity of the issues, the authors suggest that qualitative studies may be the best way of exploring limitations on reporting and the extent to which training would impact on these. Our call for further research is supported both by previous articles on this topic and by our finding that the only currently published studies are of weak quality. We would specifically like to see research into how to best design mandated notification training workshops.

The very limited extent of published evidence available so far suggests that training may positively affect the confidence and ability levels of paramedics in relation to recognising and reporting child abuse. However, the limitations of these studies need to be considered before drawing robust conclusions. While there remains the need for further research, these findings represent an exciting potential where further development of targeted training programs, including changes to the curriculum of some existing programs, may have the potential for life-saving and life-altering impacts on a primary care level for children in need.

\section{Conflict of interest}

The authors declare no competing interests. The authors of this paper have completed the ICMJE conflict of interest statement

\section{References}

1. Felitti VJ, Anda RF, Nordenberg D, et al. Relationship of childhood abuse and household dysfunction to many of the leading causes of death in adults. The Adverse Childhood Experiences (ACE) Study. Am J Prev Med 1998;14:245-58.

2. Bucci M, Marques SS, Oh D, Harris NB. Toxic stress in children and adolescents. Adv Pediatr 2016;63:403-28.

3. Lynne EG, Gifford EJ, Evans KE, Rosch JB. Barriers to reporting child maltreatment: do emergency medical services professionals fully understand their role as mandatory reporters? N C Med J 2015;76:13-8. 
4. Australian Institute of Family Studies. Child deaths from abuse and neglect. Melbourne: AIFS, 2016. Available at: https://aifs.gov.au/cfca/publications/child-deaths-abuse-andneglect [Accessed 9 March 2017].

5. Concialdi M, Read S. Child abuse neglect: mandatory reporting for EMS providers. What to look for, what to report and how. EMS World 2016;45:52-5.

6. Mathews B, Bromfield L, Walsh K, Vimpani G. Child abuse and neglect: a socio-legal study of mandatory reporting in Australia. Report for the New South Wales Department of Family and Community Services. Brisbane: Queensland University of Technology, 2015.

7. Australian Institute of Health and Welfare. Child protection Australia 2014-15. Canberra: AlHW, 2016. Available at: www. aihw.gov.au/publication-detail/?id=60129554728 [Accessed 9 March 2017].

8. Van Haeringen AR, Dadds M, Armstrong KL. The child abuse lottery: will the doctor suspect and report? Physician attitudes towards and reporting of suspected child abuse and neglect. Child Abuse Negl 1998;22:159-69.

9. Schweitzer RD, Buckley L, Harnett P, Loxton NJ. Predictors of failure by medical practitioners to report suspected child abuse in Queensland, Australia. Aust Health Rev 2006;30:298-304.

10. King B, Baker M, Ludwig S. Reporting of child abuse by prehospital personnel. Prehosp Dis Med 1993;8:67-8.

11. Markenson D, Tunik M, Cooper A, et al. A national assessment of knowledge, attitudes, and confidence of prehospital providers in the assessment and management of child maltreatment. Pediatr 2007;119:e103-8.

12. Markenson D, Foltin G, Tunik M, et al. Knowledge and attitude assessment and education of prehospital personnel in child abuse and neglect: report of a National Blue Ribbon Panel. Prehosp Emerg Care 2002;6:261-72.

13. Thomas BH, Ciliska D, Dobbins M, Micucci S. A process for systematically reviewing the literature: providing the research evidence for public health nursing interventions. Worldviews Evid Based Nurs 2004;1:176-84.

14. Liberati A, Altman DG, Tetzlaff J, et al. The PRISMA statement for reporting systematic reviews and meta-analyses of studies that evaluate health care interventions: explanation and elaboration. PLoS Med 2009;6:e1000100.

15. Weintraub B, Lazzara P, Fuchs S, Wiltsek DL. Child maltreatment awareness for prehospital providers. Int J Trauma Nurs 2002;8:81-3.

16. Stevens SL, Alexander JL. The impact of training and experience on EMS providers' feelings toward pediatric emergencies in a rural state. Pediatr Emerg Care 2005;21:12-7.

17. Gausche-Hill M. Pediatric continuing education for out-ofhospital providers: is it time to mandate review of pediatric knowledge and skills? Ann Emerg Med 2000;36:72-4.

18. Henderson DP, Gausche M, Goodrich SM, et al. Education of paramedics in pediatric airway management: effects of different retraining methods on self-efficacy and skill retention [abstract]. Acad Emerg Med 1998;5:429.

19. Bonita R, Beaglehole R, Kjellstrom T. Basic Epidemiology. 2nd edn. Geneva: World Health Organization, 2006.

20.Paramedics Australasia. Australasian competency standards for paramedics. Ballarat, Vic.: Paramedics Australasia, 2011. Available at: PA_Australasian-Competency-Standards-forparamedics_July-20111.pdf [Accessed 9 March 2017]. 